\title{
Hijos que no quieren saber nada de sus padres: ¿Una nueva causa de desheredación?
}

\author{
Crianças que não querem saber nada sobre seus pais - uma nova causa de \\ deserdação?
}

Olderchildren who wantnothing to do with theirparents - a new cause for disinheritance?

Begoña Ribera Blanes*

\section{Resumen}

Las modernas estructuras familiares favorecen situaciones de pérdida de contacto o de mala relación entre padres e hijos. La actitud de los hijos, a veces pasiva y a veces violenta, es censurada por los padres, para quienes no es suficiente con que estas conductas tengan consecuencias desde el punto de vista de la moral o la ética, sino que buscan en el ordenamiento jurídico, y más concretamente en el derecho de familia y sucesiones, para los instrumentos legales con los que hacer frente a estas inapropiadas actitudes de los hijos y les provocan sufrimiento. Nuestro Código Civil no está adaptado a la realidad social del momento, de ahí que estas actitudes de los hijos no siempre tienen encaje normativo en las causas que el ordenamiento prevé para poder extinguir la pensión alimenticia, desheredar o revocar las donaciones recibidas por estos. Mientras la reforma normativa se produce, ha sido la jurisprudencia del Tribunal Supremo la que adaptó la legislación a la realidad social, calificando el maltrato psicológico como causa de desheredación, permitiendo la revocación de donaciones por ingratitud debido al maltrato del donatario hacia el donante y confirmando que es posible extinguir la pensión alimenticia cuando la falta de relación entre padres e hijos mayores de edad sea atribuible, de modo principal y relevante, a los hijos. Queda, por lo tanto, el último paso: considerar que la ausencia de relación imputable exclusivamente a los hijos puede privarles de la parte legítima.

Palabras-clave: Desheredación. Hijos mayores de edad. Falta de relación familiar. Negativa de los hijos a relacionarse con sus padres. Imputabilidad.

\section{Resumo}

As estruturas familiares modernas são propícias a situações de perda de contacto ou de más relações entre pais e filhos. A atitude das crianças, por vezes passiva e por vezes violenta, é censurada pelos pais, estes que devem seguir um comportamento moral, ético e pensado no sistema legal para com os filhos - mais específicamente pensando o direito da familia, das sucessões e instrumentos legais - sendo considerado inadequado na forma de lidar com tais atitudes das crianças devido gerarem sofrimento a estas. O nosso Código Civil não está adaptado à realidade social atuall, razão pela qual estas atitudes por parte das crianças nem sempre têm um enquadramento normativo nas causas previstas por lei, na extinção de alimentos, deserdação ou revogação de doações destinadas a elas. Enquanto decorre a reforma regulamentar, a jurisprudência do Supremo Tribunal adaptou a legislação à realidade social, classificando os maus tratos psicológicos como causa de deserdação, permitindo a revogação das doações por ingratidão devido aos maus tratos do doador e confirmando que a possível extinsão da pensão alimentar por causa da ausência de relação entre pais e filhos em idade legal é algo atribuível. Tudo o que resta é o último passo: considerar que a ausência de uma relação atribuível, exclusivamente às crianças, pode privá-las de sua parte legítima.

Palavras-chave: Deserdação. Crianças de idade completa. Falta de relação familiar. Recusa das crianças de se relacionarem com os seus pais. Imputabilidade.

\section{Abstract}

Modern family structures are prone to situations of loss of contact or bad relationships between parents and children. The children attitude, sometimes passive and sometimes violent, is censured by parents for whom it is not enough that these behaviors have consequences from a moral or ethical point of view, but who look to the legal system, and more specifically

* Doctora la Universidad de Alicante e Profesora Titular de Derecho Civil de la Universidad de Alicante. España. E-mail: bribera@ua.es 
to the right to family and inheritance law, for the legal instruments with which to deal with these children attitudes that they consider inadequate and that cause them suffering. Our Civil Code is not adapted to the current social reality, the reason why these attitudes on the part of children do not always fit into the causes that the law provides for the extinction of the maintenance, disinheritance, or revocation of donations received by them. While the regulatory reform is taking place, it was the Supreme Court's jurisprudence that adapted the legislation to the social reality, classifying psychological mistreatment as a cause of disinheritance, allowing the revocation of donations due to ingratitude due to the donor mistreatment, and confirming that it is possible to extinguish the alimony when the lack of a relationship between parents and children of legal age is mainly and relevantly attributable to children. All that remains is the last step, which is to consider that the absence of a relationship attributable exclusively to children may deprive them of their rightful part.

Keywords: Disinheritance. Full age children. Lack of family relationship. Children's refusal to relate to their parents. imputability

\section{Introducción}

Es suficiente la ausencia de relación entre padres e hijos mantenida a lo largo del tiempo para privar a los hijos del derecho a recibir la legítima sucesoria tras el fallecimiento de sus padres? Esta es la cuestión que se debate a lo largo del artículo y que actualmente todavía se discute en la sociedad, al no haberse producido una reforma legislativa al respecto desde la aprobación del Código Civil en el año 1889.

La sociedad actual es realmente diferente a la existente en los años en que el Código Civil fue promulgado, no solo por el aumento de la esperanza de vida, que en 1900 estaba alrededor de los cuarenta años, lo que implicaba que en muchas ocasiones los hijos heredasen cuando todavía eran menores de edad, sino también por muchos otros factores sociales como los nuevos modelos familiares, las crisis matrimoniales, la globalización o la frecuente movilidad de personas por motivos laborales, causas todas ellas que han tenido un fuerte impacto en las relaciones entre padres e hijos y que en muchas ocasiones ha conllevado la desaparición de las mismas.

El problema se encuentra en que nuestro Código Civil no está adaptado para dar solución a los problemas que todas estas nuevas circunstancias puedan generar en la sociedad actual, cuestión que intenta suplirse por medio de la doctrina jurisprudencial del Tribunal Supremo, que, a través de una interpretación flexible de nuestro ordenamiento jurídico, trata de adaptar las normas del CC a la realidad social del tiempo en que han de ser aplicadas (art 3.1 CC).

El fin perseguido con este trabajo es conocer la labor de interpretación flexible llevada a cabo por el Alto Tribunal a través de las sentencias de 3 de junio de $2014^{1}$ y de 30 de abril de $2015^{2}$, en relación a las causas de desheredación, pues ha pasado de no dar cabida a la apreciación jurídica de la ausencia de relaciones paterno filiales, al quedar las mismas relegadas al campo de la moral y al tribunal de la conciencia, a integrarlas en el artículo 853.2 CC cuando las mismas produzcan un maltrato psicológico en el causante. Incluso puede defenderse, a partir de la STS de 19 de febrero de $2019^{3}$, que el Alto Tribunal va un paso más allá con la creación de una nueva causa de desheredación siempre que la falta de relación familiar sea imputable de forma principal y relevante a los hijos.

Se pretende, por tanto, conocer el criterio seguido por el Alto Tribunal en la resolución de estos casos, analizando el cambio de criterio y la creación de doctrina jurisprudencial que éste lleva a cabo.

\section{Legítimas y desheredación en el ordenamiento jurídico español}

Nuestro Código Civil no permite que el testador pueda disponer de todo su patrimonio a su antojo tras su muerte, sino que restringe su libertad testamentaria a través de legítima, definida en el artículo 806 del Código Civil como la porción de bienes de que el testador no puede disponer por haberla reservado la ley a determinados herederos, llamados por esto herederos forzosos, cuya aspiración es, desde un plano positivo, asegurar que los legitimarios perciben una parte del patrimonio, aunque ello suponga para el testador, desde un plano negativo, una limitación a la facultad de disponer de sus bienes, ya sea en su testamento ya sea a la hora de realizar donaciones, pues, como establece el artículo $636 \mathrm{CC}$, nadie puede dar ni recibir, por vía de donación, más de lo que pueda dar o recibir por testamento.

STS de 3 de junio de 2014 (RJ 2014|3900).

STS de 30 de enero de 2015 (RJ 20151639).

STS 19 febrero 2019 (RJ 20191497). 
También nuestro Tribunal Supremo aporta una definición de la legítima al conceptualizarla como "un derecho a percibir, por cualquier título, una cierta cuantía del patrimonio del causante o su valor y, en cierta medida, a ser mencionado en el testamento, quedando entonces a elección del testador el título por el que la percepción va a tener lugar o ya ha sido realizada"4.

Según estas premisas, las normas que regulan la sucesión mortis causa reservan a favor de los legitimarios una cuota del patrimonio hereditario líquido que estos pueden reclamar, tanto si no reciben los bienes que el testador les haya asignado en pago (por cualquier título sucesorio), como si estos (atendiendo a su valor) son insuficientes. Por ello, todos los bienes hereditarios están afectos al pago de las legítimas, como resulta del artículo 806 CC.

Es el Código quien nos dice, en su artículo 807, quienes ostentan la condición de herederos forzosos o legitimarios, recayendo este derecho en los hijos y descendientes respecto de sus padres y ascendientes; los padres y ascendientes en defecto de hijos y descendientes respecto de los suyos propios; y el viudo o viuda en la forma y medida que el Código establece en los artículos 834 y ss CC, asegurándose el legislador de que las atribuciones patrimoniales que reciban, estén libres de cargas y gravámenes según el art. $813 \mathrm{CC}$, salvo las permitidas por el mismo Código.

En concepto de legítima se atribuyen globalmente al grupo de legitimarios integrado por los hijos y descendientes (en línea recta) los dos tercios del haber hereditario del padre o de la madre, la llamada legítima larga. Ahora bien, el progenitor testador puede disponer libremente entre estos legitimarios del tercio de mejora. Por lo tanto, no es del todo cierto que no se pueda disponer de la legítima (art. $806 \mathrm{CC}$ ), ya que el Código sí permite al testador establecer una distribución desigual de la porción legitimaria a través de la mejora, que es la parte de legítima de que el testador puede disponer de manera desigual entre sus legitimarios (O'CALLAGHAN MUÑOZ, 2015, p. 1). Por lo tanto, en el caso de que los legitimarios sean los hijos y descendientes, la mejora será de un tercio del caudal hereditario: «el padre o la madre podrán disponer en concepto de mejora a favor de alguno o algunos de sus hijos o descendientes, ya lo sean por naturaleza, ya por adopción, de una de las dos terceras partes destinadas a la legítima», formando ambos tercios la legítima larga. Si esta se distribuye por partes iguales entre los legitimarios de primer grado, realmente no puede considerarse como mejora al no beneficiar ni perjudicar a nadie. Así las cosas, la tercera parte de la herencia se denomina parte de libre disposición y se reserva a la entera disposición del causante, quien puede disponer de tales bienes a favor de cualquier persona aunque no sea pariente.

La legítima es una institución ampliamente criticada actualmente por la doctrina. Por un lado, existe una corriente doctrinal que aboga por una reducción de su quantum al considerarlo excesivo, siendo en el caso de los hijos y descendientes de dos terceras partes del patrimonio hereditario (art. $808 \mathrm{CC})^{5}$, en el caso de padres o ascendientes la mitad del haber hereditario de los hijos o descendientes, salvo en el caso de concurrir con el cónyuge viudo, en cuyo caso será de una tercera parte de la herencia (art. 809 CC) y, en el caso del cónyuge viudo estaremos a lo dispuesto en los artículos 834 y siguientes del CC. Por otro lado, se advierten corrientes doctrinales partidarias de la supresión de la misma, dado que el fundamento histórico de la institución fue la exclusión del padre tirano que subyugaba la voluntad de sus hijos con la amenaza de la desheredación (BLASCO GASCÓ, 2018, p. 196).

Lo que sí es cierto e indiscutible es que la realidad, ya sea social, económica o física que se da en la actualidad poco o nada tiene que ver con la existente en el tiempo de redacción del Código Civil, produciéndose grandes cambios en la misma fuertemente marcados por la globalización, los nuevos modelos de familia, las crisis matrimoniales, las familias reconstituidas, la alta movilidad de personas por motivos laborales y, principalmente, por el aumento de esperanza de vida de las personas, que provoca que la transmisión de la herencia por muerte del causante se produzca cuando los legitimarios ya tienen la vida resuelta. Todos estos acontecimientos muchas veces condicionan las relaciones entre padres e hijos, provocando que en algunas ocasiones las relaciones familiares sean inexistentes, situación reconocida por el propio Tribunal Supremo en su STS de 19 de febrero de $2019^{6}$, lo que hace un sinsentido que todavía los progenitores tengan que, por imperativo legal, dejar sus bienes a aquellos hijos con los que ya no tienen ningún tipo de relación.

\footnotetext{
STS de 29 de junio de 2006 (ROJ 4636\2006).

La propuesta de Código Civil elaborada por la Asociación de Profesores de Derecho Civil (APDC) mantiene el sistema de legítimas y los legitimarios, pero propone la reducción de su quantum (hasta un tercio en el caso de descendiente único), posibilitando al testador autorizar su pago en metálico, incluso extrahereditario.

$6 \quad$ STS 19 febrero 2019 (RJ 2019/497). En el mismo sentido se pronuncia la AP de Navarra en sentencia de 27 de octubre de 2020 (ROJ 902।2020) al extinguir la pensión alimenticia de una hija mayor de edad dada su voluntad expresa en juicio oral de no querer mantener relación alguna con su padre, siendo el único interés respecto del mismo el de cobro de la pensión de alimentos.
} 
Casi siempre ocurre que el Derecho va por detrás de la realidad y en estos casos nos encontramos con una regulación obsoleta que no da respuesta a las necesidades y exigencias de la sociedad en que vivimos. Por ello, con el objetivo de dar una respuesta jurídica adecuada a los problemas existentes en las relaciones entre padres e hijos y mientras la reforma legislativa se produce, ha sido la jurisprudencia del Tribunal Supremo la que, a través de una interpretación flexible del ordenamiento jurídico, ha adaptado el mismo a la realidad social actual en la que las normas han de ser aplicadas (art. 3.1 CC).

A pesar de que la legislación española actual limita la libertad de testar del causante, es posible evadir el sistema legitimario vigente a través de la figura de la desheredación, regulada en los artículos 848 a 857 CC.

La desheredación es aquella disposición testamentaria expresa por la que el testador priva a un legitimario de participar en su herencia cuando concurra alguna de las causas que, con carácter taxativo, enuncian los arts. 852 a 855 CC (BERCOVITZ RODRÍGUEZ-CANO, 2021, p. 248). También el propio Tribunal Supremo ofrece una definición de esta institución jurídica en la sentencia de 15 de junio de $1990^{7}$ al considerarla como aquella declaración voluntaria en el testamento en el que, quien goza de la facultad de testar, priva a sus herederos forzosos del derecho a la legítima cuando concurra en ellos cualquiera de las causas legales que recoja el Código Civil de la que sean responsables. Para que la desheredación sea válida y eficaz deben darse tres requisitos: en primer lugar, debe hacerse en testamento (art. $849 \mathrm{CC}$ ); en segundo lugar, debe expresarse la causa y que esta sea una de las que admite la ley, sin que sea necesaria la descripción de hechos constitutivos ${ }^{8}$, por lo tanto, estas cláusulas constituyen un numerus clausus, no siendo posible una interpretación extensiva de las mismas, ni una aplicación analógica, y ni siquiera la argumentación minoris ad maiorem ${ }^{9}$; en tercer lugar, la causa ha de ser cierta, de manera que los herederos tendrán que probarla en juicio si el desheredado la niega ${ }^{10} \mathrm{y}$, en cuarto lugar, no debe haber mediado reconciliación entre ofensor y ofendido en los términos del artículo $856 \mathrm{CC}$, dado que esto dejaría sin efecto la desheredación hecha, pudiendo el causante volver a desheredar si se diera una nueva causa o se reitera la anterior (BERCOVITZ RODRÍGUEZ-CANO, 2012, p. 228).

En cuanto a las posibles causas por las que el testador puede privar de la legítima a sus legitimarios, sólo podrá hacerlo por aquellas que expresamente estén señaladas en la ley (art. $848 \mathrm{CC}$ ), que estén en los arts. 852 a 855 del CC, entre las que se encuentran las causas generales o aplicables a todos los legitimarios relativas a la incapacidad por indignidad para suceder (art. $852 \mathrm{CC}$ ) y las causas especiales aplicables a cada grupo concreto de herederos forzosos, ya sea a los hijos o descendientes (art. $853 \mathrm{CC}$ ), a los padres o ascendientes (art. $854 \mathrm{CC}$ ) o al cónyuge viudo (art. $855 \mathrm{CC}$ ), siendo todas ellas completadas con el artículo $852 \mathrm{CC}$.

Por razón de la temática del presente artículo nos interesan especialmente las causas de desheredación pertenecientes al primer grupo, esto es, las causas que sirven para desheredar a hijos y descendientes (art. 853 $\mathrm{CC}$ ), entre las que se incluyen como causas específicas: la negativa ilegítima (sin motivo) a prestar alimentos al padre o ascendiente que le deshereda, aunque estos no le hayan sido reclamados judicialmente (art. $853.1 \mathrm{CC}$ ) $\mathrm{y}$, en segundo lugar, los malos tratos o injurias graves de palabra (art. 853.2 CC). A estas causas deben añadirse las causas de indignidad 2, 3, 5 y 6 contempladas en el artículo 756 CC.

En el caso de que la desheredación se ajuste a los requisitos establecidos, se considerará justa y su efecto será la privación de legítima estricta de aquél que haya incurrido en alguna de las causas, pasando los hijos o descendientes del desheredado a ocupar su lugar conservando los derechos de herederos forzosos respecto a la legítima (art. $857 \mathrm{CC}$ ). La desheredación justa, sin embargo, no limita la libertad testamentaria del testador, de manera que éste puede atribuir voluntariamente a aquél un determinado bien, lo que tendría sentido cuando el bien que desea donarle el testador tiene un valor inferior al de la legítima, pudiendo pasar, aunque de manera poco probable, que el valor de dicho bien sea superior a cuanto le correspondería como legítima estricta, en cuyo caso la atribución patrimonial posiblemente deba declararse nula si de la interpretación del mismo se deduce que no fue esa la voluntad del testador, salvo que éste fuera consciente del plus valor adquirido por dicho bien.

RJ 199014760.

Si la cláusula testamentaria de desheredación de un legitimario se ampara en una causa distinta de las previstas por la ley, será nula.

STS 28 de junio de 1993 (RJ 199314792).

10 En principio la desheredación realizada por el testador se presume válida y cierta salvo que sea impugnada por el legitimario desheredado, en cuyo caso la prueba de la certeza de la causa de desheredación corresponde a los herederos del testador (STS 31 de octubre de 1995, RJ 3784). S la causa en la que se ha fundado la desheredación no se corresponde con la realidad, estaremos ante una desheredación injusta, que producirá efectos únicamente en el caso en que el legitimario injustamente desheredado no la impugne. 
Sin embargo, si la desheredación no se realiza siguiendo los requisitos establecidos, ya sea por no expresar la causa, porque la causa establecida no se encuentra entre las señaladas en los arts. 852 a $855 \mathrm{CC}$ o por no poder los herederos probar la causa que fue contradicha por el desheredado, ésta se considerará injusta, pudiendo el desheredado impugnar el testamento, anulándose de esta manera la institución de heredero en cuanto perjudique al desheredado; aunque sí valdrán los legados, mejoras y demás disposiciones testamentarias en lo que no perjudiquen a dicha legítima (art. $851 \mathrm{CC}$ ), y con efectos parecidos a la preterición intencional, aquel que fuere desheredado injustamente, tendrá, por tanto, derecho a la legítima estricta.

\section{Hacia una nueva interpretación de las causas de desheredación por parte de la jurisprudencia del Tribunal Supremo}

\subsection{El maltrato psicológico como causa de desheredación}

En sus orígenes, en la Ley de las Doce Tablas del pueblo romano, el testador debía, bien instituir herederos a ciertos familiares, o bien desheredarlos, sin necesidad de expresar causa alguna, existiendo plena libertad para testar (ALMANSA MORENO-BARREDA, 2012, p. 30). Las causas que permiten desheredar se introducen en época del emperador Justiniano, quien en su Novela 115 establece, junto a dichas causas, el sistema de legítimas (BARCELÓ DOMÉNECH, 2004, p. 475). A partir de este momento, la desheredación ya no ha vuelto a depender de la exclusiva voluntad del testador, sino que ha sido necesaria una causa legal que la contemple.

En la actualidad, nuestro Código Civil también prevé ciertas causas en las que deben incurrir los herederos para poder ser desheredados por el testador y, puesto que la desheredación se identifica con una sanción civil, la interpretación de las causas de la misma debe ser sumamente restrictiva ${ }^{11}$, algo que no solo proclama el artículo 848 del texto legal, sino también la abundante jurisprudencia, orientada en la defensa de la sucesión legitimaria, no admitiéndose: ni la analogía, ni la interpretación extintiva, ni siquiera la argumentación de "minoris ad maiorem"12. En tal sentido fue tajante la jurisprudencia al establecer que las causas de desheredación han de ser una de las específicamente determinadas por la ley cuya enumeración ha de entenderse exhaustiva, sin comprender en ella otras distintas, aun cuando guarden analogía o sean de mayor entidad, porque de otra forma, se daría al traste de con todo el sistema legitimario ${ }^{13}$.

En lo que respecta al maltrato de obra, recogido en el artículo $853.2 \mathrm{CC}$, podemos afirmar que, en un principio, lo que el legislador trataba de sancionar eran conductas de agresión o violencia física llevadas a cabo contra el causante. De hecho, antecedentes históricos nos muestran tal tendencia en el texto de Las Partidas (Ley VI, Título VIII, Partida VI), en el que la causa de desheredación se da cuando "el hijo pone las manos sobre su ascendiente" (BARCELÓ DOMÉNECH, 2004, p. 478), de ahí que la sentencia de 28 de junio de 1993 cierre sus puertas a la desheredación por falta de relación afectiva o por abandono sentimental y reserve tales hechos y circunstancias al campo de la moral, pues escapan de apreciación y valoración jurídica, y están únicamente sometidos al tribunal de la conciencia ${ }^{14}$.

Con la excusa de que tales hechos pertenecen al campo de la moral, el tribunal evita la valoración jurídica de dichas acciones, sin posibilidad de entrar a realizar un análisis y estudio sobre las circunstancias que cada caso en concreto presente y de poder entonces estimar que tales acciones hayan podido o no provocar en el ascendiente sufrimiento tal que pueda llegar a ser catalogado de maltrato psicológico, pues no todo abandono sentimental y falta de relación afectiva debe constituir maltrato psíquico. Una vez estudiado el caso concreto, de constatarse el maltrato en las acciones llevadas a cabo por el heredero, no hay razón para no encajarlo en el maltrato de obra del art. $853 \mathrm{CC}$, sin que sea obstáculo para ello el argumento de la interpretación restrictiva de las causas de desheredación (BARCELÓ DOMÉNECH, 2016, p. 289).

Los primeros cambios a este rígido criterio de interpretación aparecen con la sentencia dictada por el TS el 26 de junio de $1995^{15}$, que establece, a través de un criterio hermenéutico, no ser necesario el empleo de fuerza

\footnotetext{
STS 4 noviembre 1997(RJ 1997\7930).

STS de 28 de junio de 1993 (RJ 1993\4792).

SAP Valencia 21 de marzo de 2013 (ROJ 1583।2013)

STS de 28 de junio de 1993 (RJ 1993\4792).

STS de 26 de junio de 1995 (RJ 1995।5117).
} 
física para que pueda darse el maltrato de obra. Esta sentencia se dicta en resolución de un caso en el que la mujer del desheredado, hijo de la causante, expulsa a la madre de éste de la casa en la que vivían los tres, no adoptando el desheredado ninguna medida, lo que supuso que la causante tuviese que ocupar una vivienda cercana en estado ruinoso, con la única atención de su sobrina. El tribunal consideró que, la situación voluntaria a la que el hijo sometió a su madre a través de su conducta, en la que la obligó a vivir en condiciones precarias hasta su muerte, no prestándole la más mínima atención, sí constituía una forma de maltrato de obra, siendo justa la desheredación realizada frente al mismo.

No obstante, el sentir mayoritario de la jurisprudencia del Supremo optaba por una posición similar a la adoptada en la sentencia de 1993, en cuya línea se pronunciaba de nuevo el tribunal cuatro años más tarde, en la sentencia de 4 de noviembre de 1997, al considerar que "la no convivencia y ausencia de relación, la negativa a confortarle en sus dolencias o la inasistencia de los hijos al entierro de su padre, no pueden integrarse dentro del contenido del art. $853 \mathrm{CC}$, pues ninguno se ajusta a las agresiones físicas o injurias graves de palabra" ${ }^{16}$.

Este criterio desigual seguido por el Tribunal Supremo, ha desembocado en una contradictoria jurisprudencia de las Audiencias, y es que el "maltrato de obra" incluido en el artículo $853.2 \mathrm{CC}$ es un concepto jurídico indeterminado, dado el contenido impreciso que tales términos contienen (ALGABA ROS, 2015, p. 11). Si nos trasladamos al ámbito penal, el mismo aparece contemplado en el artículo 147.3 CP, sin embargo, tal definición, siguiendo la doctrina generalizada, no es trasladable al ámbito civil puesto que aquí no se abordan penas públicas sino privadas (BARCELÓ DOMÉNECH, 2004, p. 478). En este sentido, es la Audiencia Provincial de Palencia la que, en su sentencia de 20 de abril de 2001, da un concepto de maltrato de obra, considerándose como tal toda acción u omisión tendente a causar un menoscabo físico o psíquico, en este caso, al progenitor y testador, con el consiguiente menoscabo o sufrimiento en el que lo recibe, sin justificación inmediata en la propia actitud del testador ${ }^{17}$, pronunciándose la Audiencia Provincial de Cantabria en un sentido similar en la sentencia de 31 de enero de $2012^{18}$, contemplándose en ambas definiciones el menoscabo psíquico como modalidad incluida en el maltrato de obra.

La rigidez que caracterizaba la interpretación de las causas de desheredación por los tribunales, se vio tambaleada con la resolución dictada por el Tribunal Supremo el 3 de junio de $2014^{19}$, corroborada posteriormente por la STS de 30 de enero de $2015^{20}$, al incluir el maltrato psicológico dentro del maltrato de obra, contemplado como causa de desheredación en relación con los hijos y descendientes en el artículo 853.2 CC.

A través de la sentencia de 2014 se superan los criterios literalistas de interpretación, al acceder el Alto Tribunal a una exégesis ajustada al principio constitucional de la dignidad de la persona (art. $10 \mathrm{CE}$ ), así como a una lectura finalista y sociológica del artículo 853.2 CC (HIJAS CID, 2020, p. 78), en la que, en uso de una de las cláusulas generales de nuestro ordenamiento, el art. $3 \mathrm{CC}$, el Tribunal interpreta dicha cláusula de desheredación conforme a la realidad social del tiempo en que la misma debe ser aplicada (CARRAU CARBONELL, 2015, p. 558), conforme al signo cultural y a los valores del momento en que se producen (QUESADA PÁEZ, 2015, p. 224), estableciendo en el primer argumento de la sentencia citada que, "aunque las causas de desheredación sean únicamente las que expresamente señala la ley (art. 848 CC) y ello suponga una enumeración taxativa, sin posibilidad de analogía, ni de interpretación extensiva; no obstante, esto no significa que la interpretación o valoración de la concreta causa, previamente admitida por la ley, deba ser expresada con un criterio rígido o sumamente restrictivo. Esto es lo que ocurre con los malos tratos o injurias graves de palabra como causas justificadas de desheredación (artículo 853.2 del Código Civil), que, de acuerdo con su naturaleza, deben ser objeto de una interpretación flexible conforme a la realidad social, al signo cultural y a los valores del momento en que se producen".

En este caso, el Tribunal Supremo desestima el recurso planteado por los desheredados al considerar que sí habían incurrido en una de las causas de desheredación contempladas en la ley, basándose principalmente en cuatro argumentos.

El primero de ellos, se basa en el establecimiento por parte del Tribunal de la posibilidad de realizar una interpretación o valoración concreta de la causa, sin que ello suponga una vulneración del artículo 848 CC, de

STS de 4 de noviembre de 1997 (RJ 1997\7930).

SAP Palencia de 20 de abril de 2001 (AC 20011932).

SAP de Cantabria de 31 de enero de 2012 (AC 20121272), al ubicar dentro del maltrato de obra (...) aquellas acciones y omisiones, decididas o consentidas por el legitimario, que objetivamente colocan al causante en una situación de malestar físico o psíquico permanente e intenso.

STS de 3 de junio de 2014 (RJ 2014l3900).

STS de 30 de enero de 2015 (RJ 2015।639). 
manera que la desheredación seguirá siendo válida únicamente cuando exista una causa legal que la sustente. Con este argumento, el Tribunal permite ahora entrar a conocer el caso concreto para así poder valorar la existencia de la causa que se alega, sin que la inclusión del maltrato psicológico en el maltrato de obra suponga una nueva causa de desheredación y, por tanto, se esté vulnerando el artículo $848 \mathrm{CC}$, sino que se tratará de una mera interpretación de la causa del artículo 853.2 CC y no constituirá una nueva no prevista en el Código Civil.

El segundo argumento que el Tribunal expone, comienza con la definición del maltrato psicológico en la actualidad, entendiendo por tal aquella «acción que determina un menoscabo o lesión de la salud mental de la víctima», para después considerar que tales actuaciones están comprendidas en la expresión o dinamismo conceptual que encierra el maltrato de obra. Lo que el Tribunal realiza en este punto, es adaptar el concepto a la actualidad en que vivimos, fundamentándolo en nuestro sistema de valores y, principalmente, en la dignidad de la persona y su proyección en el marco del Derecho de familia como cauce de reconocimiento de los derechos sucesorios, especialmente de los derechos hereditarios de los legitimarios del causante, así como en el propio reconocimiento de la figura en el campo de la legislación especial, como es el caso de la Ley Orgánica de protección integral de la violencia de género, 1/2004.

El tercer argumento aportado por el Tribunal en el que se refuerza la inclusión del maltrato psicológico como una modalidad del maltrato de obra, es el criterio de conservación de los actos y negocios jurídicos como principio general del derecho ${ }^{21}$, con clara proyección en el marco del derecho de sucesiones en relación con el principio de "favor testamenti", principio considerado trascendental por ALGABA ROS (2015, p. 14), quien afirma que el testamento constituye una exteriorización de la voluntad del testador que se manifiesta cuando éste ya no está.

Por último, el Tribunal viene a concluir que, lejos de un pretendido abandono emocional, los recurrentes incurrieron en un maltrato psíquico y reiterado contra el causante del todo incompatible con los deberes elementales de respeto y consideración que se derivan de la relación jurídica de filiación. A través de este último argumento, la doctrina entiende que el tribunal ha pretendido establecer una diferenciación entre el abandono emocional y el maltrato psicológico (CARRAU CARBONELL, 2015, p. 559), ¿quiere decir entonces que la libre ruptura de relación entre padres e hijos no libera a aquéllos del deber de atribuirles la legítima sucesoria correspondiente? (CARRASCO PERERA, 2014, p. 3). Se trata de un planteamiento algo controvertido que, a pesar de suponer un avance en cuanto a la rigidez interpretativa anterior, es criticado por parte de la doctrina por la falta de claridad del mismo. En este sentido, ALGABA ROS (2015, p. 10) no coincide con la tesis mantenida en la sentencia al considerar que el abandono emocional en sí mismo, sí es relevante a efectos de considerarlo como causa de desheredación. Dado que éste se traduce en la falta de relación afectiva entre padres e hijos, existiendo un desinterés por el mayor.

Lo que en la sentencia subyace es la posibilidad de entrar a valorar el caso concreto, de manera que la ausencia de relación o el abandono emocional deberá tener entidad suficiente para que pueda llegar a considerarse maltrato psicológico (GONZÁLEZ CARRASCO, 2015, p. 289); por tanto, no se incluirá en este supuesto toda ausencia de relación, como muestra la sentencia dictada por la Audiencia Provincial de Badajoz el 5 de septiembre de 2014 en la que, atendiendo a las circunstancias concretas del caso, las actitudes llevadas a cabo por las hijas, desheredadas, no son equivalentes al maltrato psicológico en los términos expresados por el Tribunal Supremo ${ }^{22}$.

Deberá además tratarse de un comportamiento de abandono o desinterés prolongado en el tiempo, no atribuyéndolo a una situación excepcional o disputa momentánea o puntual, sino que debe ser una conducta continuada y manifiesta, así se extrae de la sentencia dictada por la Audiencia Provincial de Barcelona el 30 de abril de 2014 al expresar la misma respecto al tiempo que "la ley no exige un tiempo mínimo de ausencia de contacto, pero deberá ser significativo atendiendo a las circunstancias" y respecto a su conocimiento "deberá tratarse de una ausencia evidente y, por lo tanto, que sea conocida por terceras personas próximas al ambiente familiar de las partes" 23 .

21 STS 15 de enero de 2013 (ROJ 1153/2013) “El principio no solo se ha consolidado como un canon hermenéutico que informa a nuestro ordenamiento jurídico, con múltiples manifestaciones al respecto (...) la conservación de los contratos se erige como un auténtico principio informador de nuestro sistema jurídico que comporta, entre otros extremos, el dar una respuesta adecuada a las vicisitudes que presenta la dinámica contractual desde la preferencia y articulación de los mecanismos que anidan en la validez estructural del contrato y su consiguiente eficacia funcional, facilitando el tráfico patrimonial y su seguridad jurídica".

22 SAP Badajoz 5 de septiembre 2014 (ROJ 838\2014).

23 SAP Barcelona de 30 de abril de 2014 (ROJ 3359l2014).En sentido similar se pronuncia el Tribunal Supremo en la sentencia de 27 de junio de 2018 en la que se considera que los hechos llevados a cabo por la desheredada suponen «un hecho puntual que no integra un maltrato reiterado» afirmando además la sentencia que «solo una falta de relación continuada e imputable al desheredado podría ser valorada como causante de unos daños psicológicos», lo que nos conduce a otro de los requisitos que debe darse para que pueda apreciarse la causa, que la falta de comunicación o relación se deba al comportamiento llevado a cabo por los hijos (ROJ 249212018). 
En este sentido, se predica necesario un dolo tanto en el actuar de los mismos o como en el no actuar, al poder tratarse también de un "no hacer" y no siempre de llevar a cabo una conducta positiva, siendo tal actitud imputable en exclusiva a los desheredados como se mencionaba en la sentencia anterior y que, en igual sentido se pronuncia la Audiencia Provincial de Pontevedra el 18 de febrero de $2019^{24}$ en la que el testador "deshereda a sus seis hijos por falta de afectividad e interés que, a lo largo de las últimas décadas han tenido respecto del testador", siendo tales hechos probados a partir de la concurrencia del padre a un programa de televisión para intentar un reencuentro con sus hijos, espacio al que los hijos nunca acudieron. Dado que por el resto de pruebas quedó acreditado que los hijos fueron criados por la abuela y la tía dado el desinterés del padre durante su infancia quien no quiso contactar con ellos, la ausencia de relación es imputable al progenitor. También lo hace la Audiencia Provincial de La Coruña el 7 de marzo de 2019, que en sentido similar a la anterior, concluye que la hija desheredada había sido previamente rechazada por el testador, quien además había sido condenado en sentencia firme por agresión sexual a su hija por un tribunal suizo ${ }^{25}$, por lo que no era válida la desheredación practicada por el causante ${ }^{26}$.

En relación con el requisito anterior también se pronuncia el Tribunal Supremo en la sentencia de 13 de mayo de $2019^{27}$, al que añade que la posterior convivencia del testador con el desheredado no implica necesariamente una reconciliación entre ambos que, conforme al artículo $856 \mathrm{CC}$, deje sin efecto la desheredación realizada, sino que deberá valorarse el caso concreto, siendo razones económicas y no de cuidados y asistencia para con su madre las que motivaron, en el caso señalado, a uno de los hijos, la residencia conjunta durante los últimos meses de vida de la causante.

Meses después de dictar la citada sentencia en relación con el cambio de criterio establecido por la Sala, el Tribunal, con el mismo Magistrado Ponente, Francisco Javier Orduña Moreno, dicta una segunda sentencia con fecha de 30 de enero de $2015^{28}$ en la que copia los fundamentos jurídicos de la anterior, manteniendo así la misma doctrina en relación con la consideración del maltrato psicológico como causa de desheredación.

Así las cosas, esta segunda sentencia nos permite afirmar que nos encontramos ante verdadera jurisprudencia, ante doctrina legal del TS, al existir ya al menos dos fallos idénticos (art 1.6 CC), hasta el punto de copiar los fundamentos jurídicos de la primera en la segunda, lo que nos permite eliminar opiniones basadas en que en la primera sentencia el Tribunal trataba de aplicar justicia en un caso concreto, pero sin vocación de permanencia.

\subsection{La influencia del Derecho Foral Catalán en el cambio de criterio del TS}

Gracias a la facultad ofrecida por la CE en su artículo 149.1.8ª las Comunidades Autónomas para conservar, modificar y desarrollar sus derechos civiles, forales o especiales, el legislador catalán, a través de la Ley 10/2008 de 10 de julio ${ }^{29}$, por la que se aprueba el Libro IV del Código Civil de Cataluña, relativo a las sucesiones, incorpora como causa de desheredación en el artículo 451.17.2 e) "la ausencia manifiesta y continuada de relación familiar entre el causante y el legitimario, si es por una causa exclusivamente imputable al legitimario", coexistiendo de manera independiente con la causa prevista en el mismo artículo en el apartado c) "maltrato grave al testador, a su cónyuge o conviviente en unión estable de pareja, o a los ascendientes o descendientes del testador", en el que se incluye tanto el maltrato físico como el psíquico.

A través de esta nueva causa, independiente de la anterior, el legislador catalán intenta abarcar, entre las causas de desheredación, un ámbito de aplicación más amplio que el previsto en el derecho civil común, en el que la falta de relación paternofilial debe desembocar en maltrato psicológico en el causante para poder incluirse como causa de desheredación. De esta manera, el maltrato, ya sea físico o psíquico, será motivo de desheredación en el CCCat, amparado en la causa c) del citado artículo, pero el testador, alegando el supuesto e), podrá privar de

\footnotetext{
SAP Pontevedra 18 de febrero de 2019 (ROJ 282l2019).

SAP de La Coruña de 7 de marzo de 2019 (ROJ 327\2019).

En sentido similar se pronuncia la Audiencia Provincial de Murcia el 27 de junio de 2019 (ROJ 1125\2019), que exige probar, además de la ausencia de trato, que dicha ausencia es imputable a los hijos desheredados.

27 STS de 13 de mayo de 2019 (ROJ 1523|2019) al mencionar la misma, tras reiterar la nueva doctrina del TS sobre el maltrato psicológico, que sí incurren los herederos en el mismo al llevar una conducta "de menosprecio y abandono familiar respecto de la madre, sin justificación alguna y solo imputable a los mismos".

28 STS de 30 de enero de 2015 (RJ 20151639).

29 Ley 10/2008, de 10 de julio, del libro cuarto del Código Civil de Cataluña, relativo a las sucesiones. BOE nº 190 del 7 de agosto de 2008.
} 
legítima sin necesidad de que exista dicho maltrato, bastando para ello la ausencia de relación familiar, siempre que vaya acompañada de otros requisitos a los que posteriormente se hará referencia. De esta manera,el CCat permite desvincular la falta de relación familiar del maltrato, al contemplar la primera como causa ad hoc de desheredación, lo que evita, siguiendo la argumentación de CABEZUELO ARENAS (2019, p. 91), entrar en disquisiciones acerca de si los actos llevados a cabo por los descendientes incurren o no en maltrato.

Con carácter general puede afirmarse que esta nueva causa de desheredación ha sido acogida favorablemente por la doctrina, al suponer la misma un avance en la adaptación de la legislación a las necesidades existentes en la sociedad actual. En este sentido, considera VAQUER ALOY (2007, p. 11)que, a partir de la misma, se le reconoce al causante una mayor libertad para testar, de manera que, al privar de la legítima a aquél con quien no ha mantenido trato familiar, puede otorgarla a aquella persona que mejor le haya atendido, fundamento mantenido por la Audiencia Provincial de Barcelona en su sentencia de 30 de abril de $2014^{30}$. Sin embargo, lejos de las pretensiones y deseos manifestados por O'CALLAGHAN MUÑOZ (2015, p. 1), la inclusión de esta nueva causa fomenta la subsistencia del sistema de legítimas, al adaptar tal institución a las actuales necesidades familiares.

Más allá de las posiciones adoptadas con respecto a la norma, la doctrina y la jurisprudencia ${ }^{31}$ extraen de la literalidad de la causa varios presupuestos necesarios para la operatividad de la misma.

El primero de los requisitos está constituido por la ausencia de relación familiar que, aunque el legislador no explique en qué consiste, la misma se traduce en el inexistente contacto entre el testador y el desheredado, que ambos se hayan dejado de ver, discurriendo sus vidas por caminos diferentes, a pesar de poder existir una relación no familiar, ya sea mercantil o profesional entre los mismos, la cual no obsta para que se dé esta causa. No se deberá tener en cuenta, para la apreciación de la ausencia de relación, de acuerdo con la jurisprudencia y la doctrina mayoritaria, la convivencia o falta de la misma, pues tal y como entienden ARROYO AMAYUELAS y FARNÓS AMORÓS $(2015$, p. 16) lo normal en el momento en que nace el derecho de legítima, es que ambos no convivan, pues dadas las actuales condiciones de vida, los hijos del causante ya están dentro o cerca de alcanzar la tercera edad. A diferencia de lo que viene considerando el TS, entienden estos autores que la relación no estará rota si, por muchas desavenencias que existan, testador y legitimario conviven bajo el mismo techo o cuando se lleven a cabo visitas, aunque sean muy ocasionales. Por su parte, respecto a esta cuestión considera el TS en sentencia de 13 de mayo de $2019^{32}$, que la convivencia entre madre e hijo no es indicio de la existencia de relación entre los mismos, dado que ésta se debe simplemente a motivos económicos y que de la misma no puede inferirse una reconciliación.

En segundo lugar, la ausencia de relación referida deberá ser manifiesta y continuada. El principal problema que en relación con este requisito se plantea es la imprecisión derivada del no establecimiento por parte del legislador de un número de años concreto a partir de los cuales se pueda calificar dicha falta de relación como manifiesta y continuada, ya que no puede tenerse únicamente en cuenta lo ocurrido en la última etapa de la vida del causante, siendo el plazo de diez años el concluido por la doctrina para la apreciación de este segundo requisito (ARROYO AMAYUELAS y FARNÓS AMORÓS, 2015, p. 17). Dicha continuidad exige que la falta de relación sea sucesiva en el tiempo, no bastando una mera interrupción temporal, argumento que comparte la Audiencia Provincial de Barcelona en sus sentencias de 15 de marzo de $2012^{33}$ y de 23 de enero de $2020^{34}$. Por otra parte, en cuanto a que tal ausencia sea manifiesta, tal y como aclara la Audiencia Provincial de Barcelona en su sentencia de 30 de abril de 2014, el legislador hace referencia con ello a que sea evidente; esto es, conocido por terceras personas cercanas a la relación familiar.

Por último, el tercer requisito exigible hace referencia a que la ausencia sea imputable exclusivamente al legitimario, en otras palabras, que el causante no haya sido la causa de este alejamiento ${ }^{35}$. El mayor problema se

30 SAP Barcelona de 30 de abril de 2014 (ROJ 3359l2014). En ella se establece que el fundamento de la nueva causa "obedece a la realidad social en la que muchos hijos carecen de relación con sus padres durante mucho tiempo y en la correlativa voluntad, observada en la práctica real al otorgar testamentos, de padres que deseaban privar de su legítima a los hijos porque no ha habido relación con ellos y prefieren dar los bienes a otros familiares".

31 SAP Barcelona de 30 de abril de 2014 (ROJ 3359l2014); SAP Tarragona 18 diciembre de 2013 (JUR 2014l21780); SAP Barcelona de 13 de febrero de 2014 (RJ 2014l85318).

32 STS de 13 de mayo de 2019 (ROJ 1523।2019).

33 SAP Barcelona 15 marzo 2012 (JUR 2012\195522).

34 SAP Barcelona 23 enero 2020 (JUR 2020158332).

35 SAP Barcelona de 13 de febrero de 2014 (RJ 2014l85318). 
muestra en la demostración de este último, algo que no será fácil, y, a pesar de que en el Proyecto del CCCat se exigía que la falta de relación no se debiese a causa imputable exclusivamente al causante, en el texto definitivo se cambió el criterio, exigiendo que la ausencia de relación sea siempre imputable exclusivamente al legitimario. De esta manera, en caso de que el desheredado impugne, de acuerdo con el art. 451-20.1 CCCat, la causa de desheredación que el causante impuso contra el mismo, dentro del plazo de cuatro años desde la apertura del testamento (art. 451- 20.3 CCCat), será el heredero el encargado de demostrar no sólo la inexistencia de relación entre ambos sino también que dicha falta es exclusivamente imputable al desheredado. En caso de que el tribunal no tenga certeza de la culpa exclusiva del legitimario, debido a la interpretación restrictiva que de las mismas debe hacerse dado el espíritu sancionador subyacente en las causas, no se entenderá la concurrencia de la misma; en este sentido se pronuncia la Audiencia Provincial de Lleida el 24 de septiembre de $2014^{36}$, al concluir que la ausencia de relación no era culpa exclusiva de la hija, a la que su padre pretendía desheredar, sino que existía una situación previa negativa mantenida en el tiempo e iniciada cuando la hija era menor de edad, a consecuencia de acciones llevadas a cabo por el progenitor tales como las visitas realizadas en el domicilio familiar en estado de embriaguez, profiriendo insultos y gritos, lo que llevó al tribunal a entender que la ausencia de relación no es atribuible en exclusiva a la hija.

Esta dificultad probatoria fue prevista incluso por el mismo legislador al exponer en el Preámbulo de la ley: "A pesar de que, ciertamente, el precepto puede ser fuente de litigios por la dificultad probatoria de su supuesto de hecho, que puede conducir al juzgador a tener que hacer suposiciones sobre el origen de desavenencias familiares, se ha contrapesado este coste elevado de aplicación de la norma con el valor que tiene como reflejo del fundamento familiar de la institución y el sentido elemental de justicia que es subyacente" ${ }^{\prime 37}$.

Como propuesta de lege refrenda establecen algunos autores como ARROYO AMAYUELAS y FARNÓS AMORÓS (2015, p. 22) que lo más acertado hubiera sido prescindir del requisito de imputabilidad y atender únicamente a la falta de relación familiar. Con una opinión contraria a la expuesta se manifiesta RIBERA BLANES (2020, p. 525) al mencionar la necesidad del establecimiento de una prueba rigurosa de la causa en la que se imputa al hijo en exclusiva la ausencia de relación, puesto que, de lo contrario, el alegato de la nula relación entre hijos y padres puede convertirse en argumento fácil que sirva de excusa a los progenitores. Por su parte, PÉREZ ESCOLAR (2014, p. 1151) critica la inseguridad jurídica que la apreciación de este precepto genera, aunque la misma es menor que la existente en virtud del artículo $853.2 \mathrm{CC}$, y establece como propuesta el establecimiento de indicios por parte del testador sobre los hechos en que basa la desheredación, facilitando la probanza de los mismos a los herederos.

\subsection{La falta de relación familiar como causa de desheredación}

La desheredación, institución propia del derecho sucesorio, guarda íntima relación con la prestación alimenticia, propia del derecho de familia, debido al nexo de unión que el legislador quiso establecer entre las mismas al contemplar en el apartado cuarto del artículo 152 CC, como una de las causas de cesación de la obligación de dar alimentos, el haber incurrido el alimentista, sea o no heredero, en alguna de las faltas que dan lugar a la desheredación.

En relación con el derecho de alimentos, sí conviene diferenciar los casos en que los alimentistas sean menores, de aquellos en que sean mayores de edad, pues tal y como establece el Tribunal Supremo ${ }^{38}$, debe predicarse un tratamiento diferente en cada caso. Al ser los hijos menores de edad el deber de los padres de prestar alimentos tiene su origen en la filiación y se integra en los deberes propios de la patria potestad, presuponiendo en estos casos la necesidad de los mismos ${ }^{39}$. Una vez que los hijos hayan cumplido la mayoría de edad o se hayan

\footnotetext{
SAP Lleida 24 septiembre 2014 (JUR 2014|299298).

Preámbulo, VI legítima y cuarta viudal (párrafo 5).

STS 12 febrero 2015 (RJ 2015।338): "Se ha de partir de la obligación legal que pesa sobre los progenitores, que está basada en un principio de solidaridad familiar y que tiene un fundamento constitucional en el artículo 39.1 y $3 \mathrm{CE}$. De ahí que se predique un tratamiento jurídico diferente según sean los hijos menores de edad, o no, pues al ser menores más que una obligación propiamente alimenticia lo que existen son deberes insoslayables inherentes a la filiación, que resultan incondicionales de inicio con independencia de la mayor o menor dificultad que se tenga para darle cumplimiento o del grado de reprochabilidad en su falta de atención".

39 El Tribunal Supremo ha tachado en su reciente sentencia de 17 de marzo de 2021 (ROJ914\2021) de "violencia económica" el impago de la pensión de alimentos llevada a cabo por un padre a sus hijos menores de edad, al considerar que "el incumplimiento de esta obligación deja a los propios hijos en un estado de necesidad en el que, ante su corta edad, y carencia de autosuficiencia, necesitan de ese sustento alimenticio del obligado a prestarlo, primero por una obligación moral y natural que tiene el obligado y si ésta no llega lo tendrá que ser por obligación judicial".
} 
emancipado, momento en que se extingue la representación legal de los padres y se adquiere la capacidad plena, la obligación de alimentos no desaparece de manera automática, sino que ésta deberá seguir satisfaciéndose por el progenitor mientras se den los requisitos de convivencia y necesidad por parte de los hijos, al amparo del marco normativo de «los alimentos entre parientes», siendo de aplicación los artículos 142 y ss del Código Civil.

La obligación de prestar alimentos cesará cuando se de alguna de las circunstancias contempladas en los arts 150 y $152 \mathrm{CC}$. Entre las causas citadas conviene destacar principalmente la causa contemplada en el art. 152.4 CC, y concretamente, de entre las causas de desheredación, la prevista en el artículo 853.2 CC: "haberle maltratado de obra o injuriado gravemente de palabra", teniendo en cuenta para el desarrollo de la cuestión que se pretende abordar la doctrina jurisprudencial que se desprende de la sentencia dictada por el Tribunal Supremo de 19 de febrero de $2019^{40}$, al ser ésta la primera vez que el Alto Tribunal se pronuncia en relación con la posibilidad de integrar la ausencia de relación paterno filial como causa para extinguir la pensión alimenticia de los hijos mayores de edad, al amparo de la causa de desheredación del artículo 853.2 CC ${ }^{41}$.

En este sentido, el objeto que da lugar a la sentencia está constituido por la solicitud del padre de extinguir la pensión alimenticia que sufragaba a sus hijos al considerar que la falta de relación se integra en la causa de desheredación prevista en el artículo 853.2 CC; sin embargo, a diferencia del CCCat en el que tal ausencia sí está prevista como causa de desheredación (451.17.2 e) independiente a la del maltrato de obra (451.17.2 c), en nuestro Código Civil tal ausencia debe provocar en el causante maltrato psicológico para poder integrarse en los supuestos previstos en el maltrato de obra del artículo 853.2 CC.

A la hora de resolver el conflicto, el Alto Tribunal, lejos de basarse en el daño emocional o maltrato psicológico que en el padre hubiera podido provocar la ausencia de relación con sus hijos, actitud que podría encajar en la causa de desheredación prevista en el artículo 853.2 CC, el Tribunal Supremo opta por una interpretación flexible del artículo $853.2 \mathrm{CC}$ en base al principio de solidaridad familiar ${ }^{42}$, fundamento del derecho de alimentos entre parientes, en relación con la actitud personal de quien se considera necesitado ${ }^{43}$, interpretación que deberá hacerse conforme a la realidad social, al signo cultural y a los valores del tiempo en que han de ser aplicadas.

El Tribunal, en una extrapolación de la normativa del CCCat, admite, a través de una interpretación flexible sobre las causas de desheredación, que la falta de relación manifiesta pueda integrarse en la causa prevista en el artículo $853.2 \mathrm{CC}$ y a partir de la misma pueda extinguirse la pensión de alimentos. Sin embargo, el TS realiza una interpretación rígida y restrictiva de la concurrencia y prueba de la causa, de manera que dicha falta de relación deberá ser manifiesta e imputable, de forma principal y relevante, al hijo. La doctrina especifica que tal ausencia también debe ser continuada, pues difícil será que pueda ser conocida por terceros si no ha perdurado en el tiempo, diferenciándose del legislador catalán en la exclusividad de la causa que este último impone a los hijos, al admitir el TS que el progenitor haya podido intervenir de alguna manera, aunque con menos trascendencia, en esa falta de relación (RIBERA BLANES, 2020, p. 518). De acuerdo con dicha exigencia, dado que en el caso planteado considera el TS que no ha sido probado que la ausencia de relación se deba de forma principal y relevante a los hijos del demandante, resuelve no extinguiendo la pensión de alimentos en favor de los mismos.

La respuesta ofrecida por el Alto Tribunal en la sentencia de 2019, a través de la cual pretende adaptar los preceptos del Código a la realidad social, parece haber sido acogida de manera positiva por la doctrina debido principalmente a que la solución propuesta se adecúa en gran medida a aquello que la sociedad espera o entiende como justo en los casos en que tales problemas se plantean. En sentido positivo se pronuncia MÉNDEZ TOJO, (2019, p. 16) al considerar acertada la nueva causa de desheredación incorporada por el TS en su labor interpretativa e integradora, al propugnar a través de la misma los principios que rigen las relaciones paterno filiales.

Sin embargo, la doctrina no es unánime al respecto, siendo la crítica principal a la resolución el caso omiso que el Tribunal realiza a los preceptos que el Código establece. En este sentido, consideran que la resolución del caso por el TS debería haber ido encaminada a constatar la existencia de maltrato psíquico derivado de la ausencia de relación, puesto que, de acuerdo con las causas previstas en el Código Civil, con la jurisprudencia

40 STS 19 febrero 2019 (RJ 2019\497).

41 El fundamento jurídico segundo de la STS 19 febrero 2019 (RJ 2019l497), afirma el Tribunal: "a criterio de la sala, se encuentra justificada la necesidad de establecer jurisprudencia sobre el problema jurídico planteado por mor de la evolución de la realidad social”.

42 Este principio propio de la doctrina civilista encuentra su fundamento en el artículo 39.1 CE. No resulta innovador de esta sentencia, sino que ya había sido empleado en anteriores ocasiones por el TS, como puede apreciarse en la STS de 1 de marzo de 2001 (ROJ 1584l2001) y en la STS de 21 de septiembre de 2016 (RJ 2016/4443).

43 Idea anteriormente defendida por la STS de 21 de septiembre de 2016 (RJ 2016/4443). 
previa $^{44}$ y con parte de la doctrina, entre la que se encuentra CABEZUELO ARENAS (2019, p. 4), un mero abandono sentimental resulta intrascendente en el ámbito jurídico, debiendo éste alcanzar la magnitud de maltrato para poder considerarlo como causa de desheredación. Del mismo modo se advierte que el Tribunal no subsume los hechos en alguna de las causas del artículo $853 \mathrm{CC}$, sino que prescinde de las mismas, valiéndose de una interpretación flexible para la creación de una nueva, pues en ninguna se prevé la ausencia de relación sin maltrato psicológico como causa de desheredación, siendo un error la utilización de las causas previstas en el CCCat puesto que las mismas no se contemplan en el Código Civil, por lo que no basta que la conducta sea imputable al hijo, sino que tal conducta deberá estar prevista entre las causas de desheredación del artículo $853 \mathrm{CC}$ para que merezca el reproche jurídico pretendido (RIBERA BLANES, 2020, p. 514). En sentido similar mantiene DE LA IGLESIA MONJE (2019, p. 2992) en su análisis sobre la sentencia de $2019^{45}$ que, dado que no ha quedado probado un maltrato psicológico originado por parte de los hijos, siendo esto precisamente lo que originaría una causa de extinción de la obligación de satisfacer alimentos, deberá $\mathrm{D}$. Demetrio seguir satisfaciéndolos.

Además de los expuestos, podemos señalar como argumentos criticables a la resolución que el principio de solidaridad familiar en que el Tribunal basa su argumentación, se ve quebrado cuando el alimentista incurre en alguna de las causas de desheredación; sin embargo, dado que no incurre en ninguna de las mismas, su conducta podrá merecer otro tipo de reproche, pero no podrá provocar la privación de la pensión alimenticia, al igual que por sí sola no podría tampoco provocar la privación de la legítima (RIBERA BLANES, 2020, p. 514).

A pesar de las críticas y discrepancias entre las opiniones doctrinales, la realidad es que cada vez son más las resoluciones de Audiencias y Juzgados que acuerdan extinguir las pensiones de alimentos a favor de hijos mayores de edad que se niegan a mantener relación con el progenitor obligado al pago, siempre que se acredite que es por causa imputable exclusivamente a los hijos ${ }^{46}$. Respecto a ello, y en pro de una unificación y clarificación de la jurisprudencia, se muestra la opinión, podríamos asegurar unánime de la doctrina, sobre la necesidad de que se produzca una reforma legislativa que adapte los preceptos a la realidad social, tratando de dar respuesta a las necesidades sociales existentes hoy en día.

\section{Conclusiones}

En un primer momento el TS, en su labor de adaptar las normas a la realidad social del tiempo en que ha de ser aplicadas (art. 3.1 CC), optó por flexibilizar la interpretación de algunas causas de desheredación al entender que la ausencia de relación familiar entre padres e hijos sí constituye causa de desheredación cuando la misma incurra en maltrato psicológico (art. 853.2 CC). Sin embargo, a partir de la STS de 19 de febrero de 2019 debe considerarse que el TS ha ido más allá creado una nueva causa de desheredación que hace caso omiso del artículo 848 CC y que establece que la mera ausencia de relación familiar entre padres e hijos constituye una causa que permita el cese de la obligación de alimentos al integrarla entre las causas de desheredación. Eso sí, para la apreciación de la causa es esencial que quede probado que dicha ausencia es imputable de forma principal y relevante a los hijos, aspecto este que ha de considerarse de vital importancia, puesto que, de no ser así, podría acontecer que la falta de relación propiciada por los padres (dejadez, pasotismo) les eximiera también de prestarles alimentos y de dejarles como legitimarios la parte de la herencia que les corresponde a sus hijos.

La voluntad de nuestro Alto Tribunal está clara, poder dotar a los progenitores de instrumentos legales adecuados para responder a una actitud de los hijos que se considera injusta, y seguramente esté justificada, pero la doctrina que emana de la sentencia se considera extralimitada, ya que más que interpretar las causas establecidas en el Código Civil, lo que hace en esencia es añadir una nueva causa de desheredación no específicamente prevista, y por ende, una nueva causa para extinguir la obligación alimenticia.

44 SAP de Albacete de 14 de julio de 2016 (JUR 20161200963): "Entre las faltas que dan lugar a la desheredación, a las que se refiere el art. 152.4 del mismo Cuerpo Legal como causa de extinción de la obligación de satisfacer alimentos, no se encuentra la ausencia de relación afectiva entre alimentante y alimentista".

45 STS 19 febrero 2019 (RJ 2019\497).

46 SAP Navarra de 27 de octubre de 2020 (ROJ 902l2020) acordaba la extinción de la pensión de alimentos fundamentada en la "absoluta falta de relación entre padre e hija", imputable a la voluntad de la hija, quien expuso de manera clara, firme y taxativa" que el único contacto que quería con su padre era que le pasase la pensión. 


\section{Referencias}

ALGABA ROS, Silvia. Maltrato de obra y abandono emocional como causa de desheredación. InDret, Barcelona, n. 2, p. 1-26, 2015.

ALMANSA MORENO-BARREDA, Luis Javier. ¿Debe introducirse en el derecho civil común la "falta de relación familiar" como causa para desheredar a los hijos y otros descendientes?. Aletheia - Cuadernos Críticos del Derecho, Madrid, n. 1, p. 38-56, 2012.

ARROYO AMAYUELAS, Esther; FARNÓS AMORÓS, Esther. Entre el testador abandonado y el legitimario desheredado: ¿a quién prefieren los tribunales?. InDret, Barcelona, n. 2, p. 1-32, 2015.

BARCELÓ DOMÉNECH, Javier. La desheredación de hijos y descendientes por maltrato de obra o injurias graves de palabra. Revista Crítica de Derecho Inmobiliario, Madrid, n. 682, p. 473-520, 2004.

BARCELÓ DOMÉNECH, Javier. Abandono de las personas mayores y reciente doctrina del Tribunal Supremo español sobre la desheredación por causa de maltrato psicológico. AJI, Madrid, n. 4, p. 289-302, 2016.

BERCOVITZ RODRÍGUEZ-CANO, Rodrigo. Manual de derecho de sucesiones. Madrid: Bercal, 2012. BERCOVITZ RODRÍGUEZ-CANO, Rodrigo. Manual de derecho civil: sucesiones. Madrid: Bercal, 2021.

BLASCO GASCÓ, Francisco. Instituciones de derecho civil: derecho de sucesiones. Valencia: Tirant lo Blanch, 2018.

CABEZUELO ARENAS, Ana Laura. Maltrato psicológico y abandono afectivo de los ascendientes como causa de desheredación (art. 853.2 CC). Valencia: Tirant lo Blanch, 2019.

CABEZUELO ARENAS, Ana Laura. La supresión de las pensiones alimenticias de los hijos por negarse a tratar al progenitor pagador: relación entre el derecho de comunicación del progenitor no conviviente y la relevación de pago de los alimentos. Revista Aranzadi de derecho patrimonial, Cizur Menor, n. 49, p. 1-33, 2019.

CARRASCO PERERA, Angel. ¿Te 'ningunean' tus hijos? ¡Desherédalos!. Actualidad Jurídica Aranzadi, Cizur Menor, Navarra, n. 896, p. 1-10, 2014.

CARRAU CARBONELL, Jose María. La desheredación por maltrato psicológico y su dificultad de aplicación práctica. AJI, Madrid, n. 3, p. 555-564, 2015.

DE LA IGLESIA MONJE, María Isabel. La nula atención de los hijos hacia sus padres ¿excusa para extinguir el derecho de alimentos de padres a hijos?. Revista Crítica de Derecho Inmobiliario, Madrid, n. 776, p. 29872998, 2019.

GONZÁLEZ CARRASCO, María del Carmen. Desheredación por maltrato psicológico: sentencia del Tribunal Supremo (Sala de lo Civil, Sección 1ª) de 3 junio 2014 (RJ 2014, 3900). CCJC, Madrid, n. 97, p. 289-298, 2015.

HIJAS CID, Eduardo. Repercusiones del maltrato psicológico en la desheredación un lustro después. EI Notario del Siglo XXI, Madrid, n. 89, 2020. Disponible en: https://www.elnotario.es/hemeroteca/revista-89/9887repercusiones-del-maltrato-psicologico-en-la-desheredacion-un-lustro-despues. Consultado el: 8 nov. 2021.

MÉNDEZ TOJO, Ramón. Extinción de la pensión de alimentos a favor de los hijos mayores de edad: la novedosa STS 104/2019, de 19 de febrero. Actualidad civil, Madrid, n. 6, p. 1-16, 2019.

O'CALLAGHAN MUÑOZ, Xavier. A vueltas con la desheredación y a revueltas con la legítima. Diario la Ley, Madrid, n. 8592, p. 1-6, 2015.

PÉREZ ARROYO, Olga. El maltrato psicológico de los hijos hacia sus padres, como nueva causa de desheredación: una aproximación jurídica, mediática y de interés humano. Derecom, Madrid, n. 24, p. 97-121, 2018. 
PÉREZ ESCOLAR, M. Causas de desheredación y flexibilización de la legítima. En: HERRERO OVIEDO, Margarita; DOMÍNGUEZ LUELMO, Andrés; GARCÍA RUBIO, María Paz. Estudios de derecho de sucesiones. Madrid: Wolters Kluwer, 2014. p. 1131-1154.

QUESADA PÁEZ, Abigail. Legítimas y desheredación. Revista Aranzadi Doctrinal, Cizur Menor, n. 3, p. 209229, 2015.

RIBERA BLANES, Begoña. La falta de relación afectiva entre padres e hijos mayores de edad como causa de extinción de la pensión de alimentos. AJI, Madrid, n. 13, p. 482-528, 2020.

VAQUER ALOY, Antoni. Reflexiones sobre una eventual reforma de la legítima. InDret, Barcelona, n. 3, p. 1-25, 2007.

Recebido em: 29.10 .2021

Aceito em: 24.11.2021 